\title{
The Role of Carrageenan and Carboxymethylcellulose in the Development of Intestinal Inflammation
}

\author{
John Vincent Martino ${ }^{1}$, Johan Van Limbergen ${ }^{1,2 *}$ and Leah E. Cahill ${ }^{2,3}$ \\ ${ }^{1}$ Pediatric Gastroenterology, Hepatology and Nutrition, IWK Health Centre, Halifax, NS, Canada, \\ ${ }^{2}$ Medicine, Dalhousie University, Halifax, NS, Canada, ${ }^{3}$ Nutrition, Harvard T.H. Chan School of Public Health, \\ Boston, MA, USA
}

\section{OPEN ACCESS}

Edited by: Séamus Hussey,

Our Lady's Children's Hospital, Ireland

Reviewed by:

Christiane Sokollik,

University Children's Hospital

Bern, Switzerland

Moftah Hussin Alhagamhmad,

University of New South Wales,

Australia

*Correspondence:

Johan Van Limbergen johanvanlimbergen@dal.ca

Specialty section:

This article was submitted to Pediatric Gastroenterology, Hepatology and Nutrition, a section of the journal

Frontiers in Pediatrics

Received: 11 March 2017

Accepted: 13 April 2017

Published: 01 May 2017

Citation:

Martino JV, Van Limbergen J and Cahill LE (2017) The Role of

Carrageenan and

Carboxymethylcellulose in the

Development of Intestinal Inflammation.

Front. Pediatr. 5:96.

doi: 10.3389/fped.2017.00096
Although the exact pathophysiology remains unknown, the development of inflammatory bowel disease (IBD) is influenced by the interplay between genetics, the immune system, and environmental factors such as diet. The commonly used food additives, carrageenan and carboxymethylcellulose (CMC), are used to develop intestinal inflammation in animal models. These food additives are excluded from current dietary approaches to induce disease remission in Crohn's disease such as exclusive enteral nutrition (EEN) using a polymeric formula. By reviewing the existing scientific literature, this review aims to discuss the role that carrageenan and CMC may play in the development of IBD. Animal studies consistently report that carrageenan and CMC induce histopathological features that are typical of IBD while altering the microbiome, disrupting the intestinal epithelial barrier, inhibiting proteins that provide protection against microorganisms, and stimulating the elaboration of pro-inflammatory cytokines. Similar trials directly assessing the influence of carrageenan and CMC in humans are of course unethical to conduct, but recent studies of human epithelial cells and the human microbiome support the findings from animal studies. Carrageenan and CMC may trigger or magnify an inflammatory response in the human intestine but are unlikely to be identified as the sole environmental factor involved in the development of IBD or in disease recurrence after treatment. However, the widespread use of carrageenan and $\mathrm{CMC}$ in foods consumed by the pediatric population in a "Western" diet is on the rise alongside a corresponding increase in IBD incidence, and questions are being raised about the safety of frequent usage of these food additives. Therefore, further research is warranted to elucidate the role of carrageenan and CMC in intestinal inflammation, which may help identify novel nutritional strategies that hinder the development of the disease or prevent disease relapse post-EEN treatment.

Keywords: carboxymethylcellulose, carrageenan, inflammatory bowel disease, microbiota, Crohn's disease, ulcerative colitis

\section{INTRODUCTION}

Crohn's disease (CD) is a chronic relapsing and remitting inflammatory bowel disease (IBD) that causes damage to the mucosal lining of the gastrointestinal tract, resulting in abdominal pain, (bloody) diarrhea, intestinal ulceration, and often progression toward stricturing/penetrating complications requiring surgery, malnutrition, impaired growth, disability, and even mortality $(1,2)$. Epidemiological 
studies have shown an increasing incidence of IBD [composed of $\mathrm{CD}$ and ulcerative colitis (UC)] both in areas of the world where the disease has been originally more prevalent (North America, Australia, and Europe) and in countries where IBD was previously infrequent (Asia and South America) $(3,4)$. It is noteworthy that this increase has occurred in conjunction with the transition toward a "Western" diet characteristically high in processed foods and fats and low in fruits and vegetables (5). Although the exact etiology and pathogenesis of IBD remain obscure, it is believed to result from a combination of genetic, microbial, immunological, and environmental factors including diet (6). In the last couple of years, the field of nutrition in IBD has advanced substantially $(7,8)$, with several dietary aspects of interest including the food additives used to induce intestinal inflammation and ulceration in animal models of IBD (9-11).

Food additives are substances intentionally added during production, processing, packaging, transportation, or storage of commercial food products. Carrageenan is the name referring to a family of high-molecular-weight sulfated polysaccharides extracted from seaweeds and commonly used as a thickening and emulsifying food additives to improve the texture of commercial food products including infant formulas, dairy products, milk alternatives such as almond milk, processed meats, and soy-based products $(9,12)$. First patented in the United States in the 1930s, carrageenan's use as a food additive in the Western diet has been substantially increasing over the last 50 years $(9,13)$. Carboxymethylcellulose (CMC) is a derivative of cellulose, making it affordable and abundant with thickening and emulsifying qualities, and it is found vastly throughout the commercial food industry with a progressive annual increase in its usage as a food additive $(14,15)$.

\section{THE ROLE OF CARRAGEENAN IN INTESTINAL INFLAMMATION IN ANIMAL MODELS}

It has been demonstrated that when guinea pigs are supplied with degraded carrageenan in their drinking water, ulcerations develop in $100 \%$ of the animals in their large intestine by the end of a 30-day period (16). The lesions induced by carrageenan in the guinea pigs' large bowel resemble features of human UC (10). Carrageenan has also produced ulcerative lesions in rabbits, mice, and rats that were associated with weight loss, anemia, diarrhea, visible or occult blood, and sometimes mucus in the feces (17). Further, macroscopic features reminiscent of human UC, such as ulcerations predominantly limited to the mucosa along with pseudopolyps and polypoidal formations, were observed, as well as features commonly seen in $\mathrm{CD}$ such as strictures in the small intestine leading to obstruction (17). Histological changes associated with exposure to carrageenan in animal models include acute, subacute, and chronic inflammatory changes in the mucosa; occasional crypt abscesses; cystic dilatation or distortion of mucosal glands; mucosal ulceration in various stages of progression and healing; and hyperplastic changes of the glandular epithelium (17). Pricolo et al. noted that animals fed a $2 \%$ solution of carrageenan mixed with standard rat chow developed small bowel lesions first (from 2 to 6 weeks) followed by colonic lesions that developed after 8 weeks (11), which may be of particular interest for a subgroup of human CD patients who extend their disease location (18-20).

In recent years, evidence from animal studies has been mounting to suggest that the gut microbiome plays a critical role in the development of inflammation in response to exposure to carrageenan. For example, guinea pigs fed degraded carrageenan develop cecal ulcerations within 21-30 days after carrageenan treatment (21), whereas germ-free guinea pigs fed carrageenan for 6 months or more do not develop any intestinal lesions (22). Concurrent treatment of conventional guinea pigs with carrageenan and metronidazole, an antimicrobial primarily active against anaerobic bacteria, has been shown to prevent the development of intestinal ulcerations $(22,23)$. Consistent with recent reports in human IBD $(24,25)$, microorganisms such as Bacteroides vulgatus appear to play an important role in the development of the experimental ulcerative lesions in animals (26). For example, animals who were immunized with $B$. vulgatus, prior to carrageenan administration developed experimental disease at a faster rate and more severe lesions than animals that were administered carrageenan alone $(23,27)$. Mirroring the development of antibodies to components of the intestinal microbiome in human $\operatorname{IBD}(28,29)$, Onderdonk et al. noted that non-immune carrageenan recipients developed antibodies to $B$. vulgatus during carrageenan treatment, implying that an adaptive immune response occurs in the animals following carrageenan-induced intestinal ulceration $(26,27)$. Factors present on the bacterial outer membrane may mediate these antibody responses, as one study assessed eight strains of $B$. vulgatus and observed the alpha phenon (term used to reflect strain variation of outer membrane proteins) was associated with the enhancement of colitis (30).

The specific mechanism by which carrageenan induces inflammation in experimental animal models is not clearly defined, but carrageenan has been demonstrated to decrease the amount of epithelial glycoproteins in the colon (31) and is capable of inhibiting the interaction between macrophages and lymphocytes (32). The involvement of toll-like receptor-4 (TLR4) and interleukin (IL)-6 in the innate immune response to carrageenan was demonstrated using TLR4- and myeloid differentiation primary response 88-deficient mice (33). Recently, Wei et al. showed in a trinitrobenzenesulfonic acid (TNBS) model of colitis in BALB/c mice that pretreatment with carrageenan aggravated the severity (both clinical and histological) of TNBS colitis, with a concomitant increased expression of IL- 6 and tumor necrosis factor alpha (TNF)- $\alpha$ and a reduction in IL-10 (34). Taken together, these animal studies have led to the hypothesis that food emulsifiers such as carrageenan may act as a conditional inflammatory agent that magnifies any existing chronic inflammation of the intestinal tract provoked by pathogens (35). This hypothesis explains why carrageenan has been found to induce intestinal inflammation in most animal studies, but not all. For example, healthy neonatal pigs fed infant formula with carrageenan for 28 days had no effect on blood cytokine evaluations (IL-1 $\beta$, IL-6, IL-8, and TNF- $\alpha$ ) (36), but they would not have had any baseline inflammation and were not exposed to pathogens. 


\section{THE ROLE OF CMC IN INTESTINAL INFLAMMATION IN ANIMAL MODELS}

In mice given relatively low concentrations of $\mathrm{CMC}$, low-grade inflammation and obesity/metabolic syndrome was induced in wild-type hosts and promoted robust colitis in IL-10 $0^{-/}$and TLR5 ${ }^{-/-}$mice. In the control mice not fed CMC, the closest bacteria were shown to reside about $25 \mu \mathrm{m}$ from epithelial cells with no bacteria observed within $10 \mu \mathrm{m}$, whereas CMC-treated mice exhibited some bacteria in apparent contact with the epithelium, and the average distance was reduced by more than $50 \%$ (37). In this study, CMC dramatically altered microbiota composition in both fecal and intestinal-adherent bacteria, and the authors concluded that chronic exposure to CMC resulted in erosion of the protective function of the mucus, increased bacterial adherence, and a more pro-inflammatory microbiota (37). More recently, Chassaing et al. tried to disentangle the effect of inflammation itself on microbiota composition from the effect of CMC on host parameters (that in turn promotes inflammation and subsequently alters the microbiota). They used the Mucosal Simulator of the Gastrointestinal Microbial Ecosystem (M-SHIME) model to examine the effects of emulsifiers on the human microbiota in vitro (38). CMC directly acted upon human microbiota to increase its pro-inflammatory potential; the CMC-induced increase in flagellin occurred after 1 day and was driven by altered microbiota gene expression rather than microbiota composition changes (38). Transfer of both emulsifier-treated M-SHIME microbiotas to germ-free recipient mice recapitulated many of the host and microbial alterations observed in mice directly treated with emulsifiers, notably the development of intestinal inflammation (38). These results suggest that the microbiota may be a key direct target of CMC to drive chronic intestinal inflammation.

Swidsinski et al. have demonstrated that exposure to $2 \% \mathrm{CMC}$ in IBD-susceptible IL-10 gene-deficient mice results in "CD-like effects", reporting that changes in the CMC-treated mice were identical to ileal biopsy findings of CD patients (14). This was supported by the observations that mice treated with $2 \% \mathrm{CMC}$ demonstrated increased concentrations of bacteria in the ileum, larger spaces between villi, increased amounts of bacteria adherent to the villi, increased white blood cells in the lumen, and, in some of the mice, bacterial infiltration of the epithelium (14).

These findings of the effects of commonly used emulsifiers on the microbiota, mucus layer, and epithelial barrier integrity should be considered in conjunction with the recent work by Desai et al. (39) regarding the role of dietary fiber on mucus barrier maintenance. These authors demonstrated that in gnotobiotic mice colonized with a synthetic human gut microbiota and denied dietary fiber, the microbiota will consume host-secreted mucus glycoproteins as a nutrient source in place of fiber, leading to erosion of the colonic mucus barrier (39). In turn, this erosion of the colonic mucous barrier promoted greater epithelial access and lethal colitis by the murine pathogen Citrobacter rodentium (39). Carrageenan and CMC are often added to commercial food products as a fiber (40), instead of other dietary fiber (such as water-insoluble cellulose and resistant starch or water-soluble fiber such as pectin and raffinose) sources. In addition, many CD patients already limit dietary fiber to avoid its bulk-forming and laxative effects. Therefore, a "perfect storm" setting in which CD patients increase their CMC/carrageenan intake but limit their intake of other dietary fibers is created, which could propagate or exacerbate the existing dysbiosis toward more mucin-degradation and which could enhance the susceptibility for mucosa-associated pathogens.

\section{FOOD ADDITIVES AND INTESTINAL INFLAMMATION IN HUMANS}

The reports above of commonly used food additives causing intestinal inflammation in animal models have triggered investigations of how they may lead to inflammation in the human gastrointestinal tract, although perfectly corresponding human studies are of course unethical to conduct. It is likely that mechanisms by which carrageenan induces inflammation in the human intestine are similar to animals and multifactorial: the stimulation of pro-inflammatory cytokines, the disruption of the epithelial barrier, and the interference with innate mucosal immune responses to microorganisms (Figure 1). Community-level metabolic networks within the microbiome produce bioactive metabolites that have an established role in intestinal immune homeostasis and a healthy gut mucosal barrier $(41,42)$. This barrier protecting the host from luminal antigens is composed of enterocytes (epithelial cells) and the seal between them provided by the tight junctions (43). With a healthy gut mucosal barrier, an individual maintains a homeostasis where the passage of nutrients, ions, and water across the intestinal epithelium into the mesenteric blood stream is tightly regulated, while translocation of dietary antigens and components of the microbiome is prevented (43), and the active crosstalk between a diverse microbiome and the intestinal immune system leads to immune tolerance. Impaired barrier function can lead to abnormalities in the expression of tight junction protein that may trigger immune activation and the development of inflammatory disease in susceptible individuals $(43,44)$.

Borthakur et al. provided the first report of the inflammatory response of human intestinal epithelial cells to carrageenan exposure by demonstrating that carrageenan stimulates an inflamatory cascade in colonic epithelial cells in a pathway involving B-cell lymphoma/leukemia 10 gene $(\mathrm{Bcl10})$ activation and the increased production of IL-8 (9), a key pro-inflammatory cytokine. These results were supported when Choi et al., using the human colonic adenocarcinoma cell line HCT-8, demonstrated that carrageenan led to the activation of nuclear factor kappaB, which subsequently increased the gene induction of IL-8 (12). In addition, they reported that carrageenan triggered a disruption of the epithelial barrier, decreasing the density of tight junctional protein zonula occludens ( $\mathrm{ZO})-1$, causing disarray in the distribution of ZO-1 throughout the epithelium, and decreasing the gene expression of this tight junction protein (12). More recently, this group showed that carrageenan exposure triggered the expression of the proapoptotic macrophage inhibitory cytokine 1 (MIC1), which is in turn counteracted by MIC1-induced expression of activating transcription factor 3 (45). 


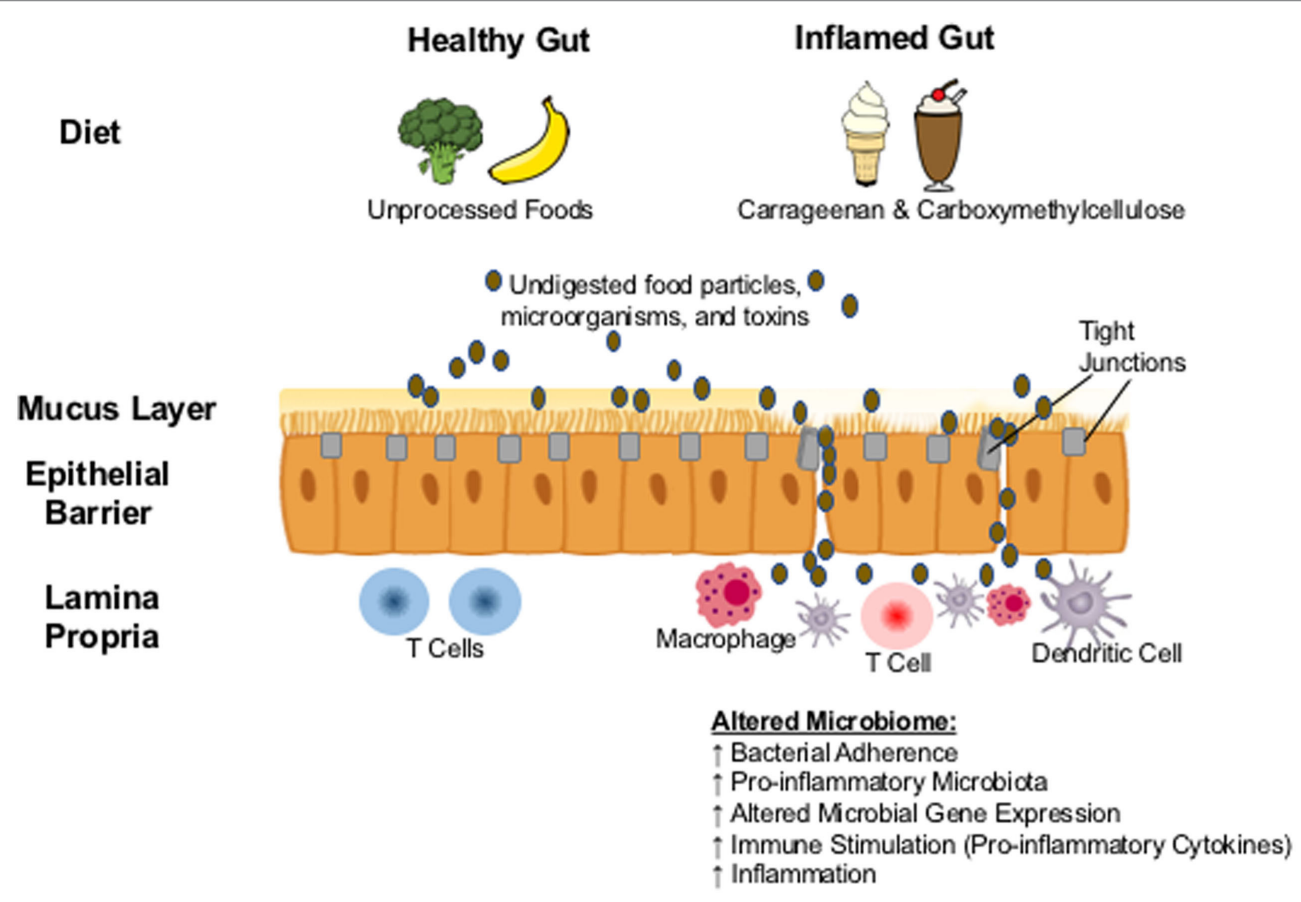

FIGURE 1 | Proposed biological mechanism: carrageenan and carboxymethylcellulose in processed foods result in the erosion of the protective mucus layer and in the abnormal expression of tight junction proteins. Undigested food particles, toxins, and microorganisms are then able to pass though the intestinal epithelium resulting in translocation of microbes and the overcolonization by pathobionts that can alter the composition of the gut microbiome, triggering the activation of the immune system and the development of inflammation.

Carrageenan has been reported to interact with the glycoprotein deleted in malignant brain tumors 1 (DMBT1). DMBT1 functions as a pattern recognition molecule with a peptide domain capable of binding and aggregating a wide spectrum of bacteria (46) and has been demonstrated to prevent the invasion of bacteria into intestinal epithelial cells in vitro (47). Carrageenan inhibits the bacterial aggregating function of DMBT1 via binding to the specific peptide that recognizes bacteria, and it has been suggested that carrageenan disrupts the mucosal protection provided by DMBT1 (48). This raises the possibility that carrageenan is capable of disrupting an innate mucosal immune function provided by DMBT1, which can then trigger the initiation or perpetuation of an inflammatory response to intestinal bacteria or bacterial antigens (48).

In human cells, carrageenan has also been demonstrated to trigger innate immune responses through pathways that involve Bc110, TLR4, NF- $\kappa$ B, and AP-1 $(9,35,49)$, leading to the upregulation of TNF- $\alpha$ secretion (50). For example, Jiang et al. (51) demonstrated that carrageenan-induced TNF- $\alpha$ secretion is the main contributor to cellular damage in Caco-2 monolayers exposed to carrageenan. However, researchers in the field note that in these studies, the degree of inflammation caused by carrageenan alone is low, while the inflammation generated through these pathways when a pathogen is additionally present is high, supporting the hypothesis that an interaction effect is present in which carrageenan serves as a pro-inflammatory agent to amplify existing intestinal inflammation (35).
In view of the recent benchmark reports by Chassaing et al. (38) and Desai et al. (39), more studies of the intestinal response to the widely used emulsifiers, carrageenan and CMC, together with other features of a Western diet such as reduced dietary fiber intake are eagerly awaited (52). It is noteworthy that the Food and Drug Administration regulations do not contain a definition of dietary fiber but rather have relied on analytical methods for measuring levels of dietary fiber present in food. Therefore, an isolated or synthetic non-digestible carbohydrate such as carrageenan and CMC can be added to foods and quantified as a dietary fiber even if it does not provide the beneficial physiological effect to human health that dietary fiber should provide. For example, CMC is listed among the 26 most common fibers being added to food and declared on the Nutrition Facts label as dietary fiber (40).

\section{WIDESPREAD USE OF FOOD ADDITIVES}

Patented in the United States in the 1930s, carrageenan was granted GRAS (generally regarded as safe) status in 1959 and currently remains included as a food additive that holds GRAS status in the Code of Federal Regulations in the United States (13). Carrageenan acts to thicken, stabilize, and emulsify a wide variety of foods typically consumed in the Western diet including dairy products such as chocolate milk, ice cream, cottage cheese, sour cream, and yogurt; processed meats; soymilk; almond milk; mayonnaise; and infant formula (53). Estimates regarding the average daily intake of carrageenan vary from 20 to $200 \mathrm{mg} /$ day 
$(13,54)$ and are currently difficult to put into context without a standard for comparison within human studies or with animal studies.

Carboxymethylcellulose is used broadly throughout the food industry in products typically consumed by children including candy, chewing gum, "snack foods," ketchup, and various baked goods, and currently, there are no quantitative restrictions on its use nor does its addition to food require to be declared $(14,15)$. CMC is listed in the Food and Drug Administration's database of GRAS substances (55), and CMC is also included in the Safety and Toxicity of Excipients for Paediatrics (STEP) database $(56,57)$, a resource developed by the European Paediatric Formulation Initiative and the United States Paediatric Formulation Initiative in collaboration for storage and rapid/effortless access to the safety and toxicological data of commonly used excipients.

\section{ROLE OF DIET IN IBD: EPIDEMIOLOGY AND TREATMENT}

The increasing incidence rate of IBD worldwide, with the highest incidence and prevalence being in Westernized countries (3), has been associated with increased consumption of a Western diet (5). A case-control study conducted in Japan assessed environmental risk factors for UC in 101 patients and observed that consumption of foods typical of a Western diet including bread, butter, and sausage was significantly related to an increase in UC risk (58). Moreover, D'Souza et al. demonstrated that the consumption of fried and fast foods, meats, snacks, and desserts, which they labeled as a traditional Western dietary pattern, increased the likelihood of acquiring CD in adolescent females (59). Conversely, they found that both males and females exposed to a prudent dietary pattern, consisting of mostly vegetables, fish, grains, and nuts, had a decreased likelihood of developing CD (59).

Exclusive enteral nutrition (EEN) is recommended as a firstline therapy in pediatric CD and involves the use of a liquid formula diet as the only source of nutrition over several weeks $(8,60)$.The mechanism of action of EEN has not been clearly established; however, it may provide efficacy via eliminating certain components of the Western diet and through modulation of the microbiome (61-67). More recently, novel dietary therapy regimens have been described, which involve avoidance of processed foods such as the CD exclusion diet (CDED) (68) and the Specific Carbohydrate Diet (69). Sigall-Boneh et al. demonstrated that the CDED, which avoids exposure to many components of a Western diet such as dairy products and processed foods containing food additives, led to remission in $70 \%$ of patients (8). Through large network studies such as the Canadian Institutes for Health Research supported Inflammation, Microbiome, Alimentation, GastroIntestinal and Neuropsychiatric effects (IMAGINe), considerable efforts are being made to investigate the potential contributions of dietary factors to IBD pathophysiology as a dysregulated interplay of genetic, environmental, microbial, and immunological factors $(6,59)$, and so more details on the role of diet, including food additives such as carrageenan and CMC, in IBD may be discovered in the near future and inform dietary recommendations and medical treatment of IBD.

\section{CONCLUSION}

Carrageenan and CMC administered in animal models consistently result in intestinal ulcerations with histopathological features similar to human IBD. Although the set of precise mechanisms through which these emulsifiers induce lesions and inflammation remains unknown, disruption of the epithelial barrier and dysregulation of the immune response to the gut microbiome have been repeatedly implicated. These findings raise concern because carrageenan and CMC are used extensively in processed food products that are consumed by the pediatric population, and the incidence rate of childhood IBD is increasing concurrently with a rise in the adoption of a Western diet. The only successful dietary interventions to have induced $\mathrm{CD}$ remission exclude processed foods containing carrageenan and $\mathrm{CMC}$, further supporting the possibility that carrageenan and $\mathrm{CMC}$ are potential triggering or magnifying substances of inflammation in IBD. Further research is warranted to clarify the role of carrageenan and CMC in the microbiome alteration of intestinal inflammation together with an improved appreciation of the complex interplay with the consumption of dietary fibers, and such studies could lead to novel nutritional strategies that help prevent the development of IBD or help induce and sustain remission.

\section{AUTHOR CONTRIBUTIONS}

All authors listed have made substantial, direct, and intellectual contribution to the work and approved it for publication.

\section{ACKNOWLEDGMENTS}

The authors would like to thank Leah Boulos from the Maritime SPOR SUPPORT Unit for her instruction to JM on literature searching and journal article extraction for this review.

\section{FUNDING}

JVL was supported by a NASPGHAN/CCFA Young Investigator Development award (2013-2015), a Nova Scotia Health Research Foundation (NSHRF) establishment award (2015-2017), a Future Leaders in Inflammatory Bowel Disease (FLIBD) Program grant (2015-2016), a Dalhousie Medical Research Foundation equipment grant (2015-2016), a donation from the MacLeod family, an IWK Health Centre Research Associateship and Cat. $B$ grant and a Canadian Institutes of Health Research (CIHR)CAG-CCC New Investigator Award (2015-2020: 201412XGP340307-205026) and a Canadian Foundation of Innovation John R. Evans Leadership fund (\#35235). JVL is supported by a CIHRSPOR-Chronic Diseases grant (Inflammation, Microbiome, and Alimentation: Gastro-Intestinal and Neuropsychiatric Effects: the IMAGINE-SPOR chronic disease network). 


\section{REFERENCES}

1. Wolters FL, Russel MG, Sijbrandij J, Schouten LJ, Odes S, Riis L, et al. Crohn's disease: increased mortality 10 years after diagnosis in a Europe-wide population based cohort. Gut (2006) 55(4):510-8. doi:10.1136/gut.2005.072793

2. DeBoer MD, Denson LA. Delays in puberty, growth, and accrual of bone mineral density in pediatric Crohn's disease: despite temporal changes in disease severity, the need for monitoring remains. J Pediatr (2013) 163(1):17-22. doi:10.1016/j.jpeds.2013.02.010

3. Thia KT, Loftus EV Jr, Sandborn WJ, Yang SK. An update on the epidemiology of inflammatory bowel disease in Asia. Am J Gastroenterol (2008) 103(12):3167-82. doi:10.1111/j.1572-0241.2008.02158.x

4. Benchimol EI, Fortinsky KJ, Gozdyra P, Van den Heuvel M, Van Limbergen J, Griffiths AM. Epidemiology of pediatric inflammatory bowel disease: a systematic review of international trends. Inflamm Bowel Dis (2011) 17(1):423-39. doi:10.1002/ibd.21349

5. Hou JK, Abraham B, El-Serag H. Dietary intake and risk of developing inflammatory bowel disease: a systematic review of the literature. Am J Gastroenterol (2011) 106(4):563-73. doi:10.1038/ajg.2011.44

6. Penagini F, Dilillo D, Borsani B, Cococcioni L, Galli E, Bedogni G, et al. Nutrition in pediatric inflammatory bowel disease: from etiology to treatment. A systematic review. Nutrients (2016) 8(6):334. doi:10.3390/nu8060334

7. Reif S, Klein I, Lubin F, Farbstein M, Hallak A, Gilat T. Pre-illness dietary factors in inflammatory bowel disease. Gut (1997) 40(6):754-60. doi:10.1136/ gut.40.6.754

8. Sigall-Boneh R, Pfeffer-Gik T, Segal I, Zangen T, Boaz M, Levine A. Partial enteral nutrition with a Crohn's disease exclusion diet is effective for induction of remission in children and young adults with Crohn's disease. Inflamm Bowel Dis (2014) 20(8):1353-60. doi:10.1097/MIB.0000000000000110

9. Borthakur A, Bhattacharyya S, Dudeja PK, Tobacman JK. Carrageenan induces interleukin-8 production through distinct Bcl10 pathway in normal human colonic epithelial cells. Am J Physiol Gastrointest Liver Physiol (2007) 292(3):G829-38. doi:10.1152/ajpgi.00380.2006

10. Anver MR, Cohen J. Animal model of human disease. Ulcerative colitis. Animal model: ulcerative colitis induced in guinea pigs with degraded carrageenan. Am J Pathol (1976) 84(2):431-4.

11. Pricolo VE, Madhere SM, Finkelstein SD, Reichner JS. Effects of lambdacarrageenan induced experimental enterocolitis on splenocyte function and nitric oxide production. J Surg Res (1996) 66(1):6-11. doi:10.1006/ jsre.1996.0364

12. Choi HJ, Kim J, Park SH, Do KH, Yang H, Moon Y. Pro-inflammatory $\mathrm{NF}-k a p p a B$ and early growth response gene 1 regulate epithelial barrier disruption by food additive carrageenan in human intestinal epithelial cells. Toxicol Lett (2012) 211(3):289-95. doi:10.1016/j.toxlet.2012.04.012

13. Tobacman JK. Review of harmful gastrointestinal effects of carrageenan in animal experiments. Environ Health Perspect (2001) 109(10):983-94. doi:10.1289/ehp.01109983

14. Swidsinski A, Ung V, Sydora BC, Loening-Baucke V, Doerffel Y, Verstraelen H, et al. Bacterial overgrowth and inflammation of small intestine after carboxymethylcellulose ingestion in genetically susceptible mice. Inflamm Bowel Dis (2009) 15(3):359-64. doi:10.1002/ibd.20763

15. Swidsinski A, Loening-Baucke V, Herber A. Mucosal flora in Crohn's disease and ulcerative colitis - an overview. J Physiol Pharmacol (2009) 60(Suppl 6):61-71.

16. Watt J, Marcus R. Carrageenan-induced ulceration of the large intestine in the guinea pig. Gut (1971) 12(2):164-71. doi:10.1136/gut.12.2.164

17. Watt J, Marcus R. Experimental ulcerative disease of the colon in animals. Gut (1973) 14(6):506-10. doi:10.1136/gut.14.6.506

18. Meinzer U, Ideström M, Alberti C, Peuchmaur M, Belarbi N, Bellaïche M, et al. Ileal involvement is age dependent in pediatric Crohn's disease. Inflamm Bowel Dis (2005) 11(7):639-44. doi:10.1097/01.MIB.0000165114.10687.bf

19. de Bie CI, Paerregaard A, Kolacek S, Ruemmele FM, Koletzko S, Fell JM, et al. Disease phenotype at diagnosis in pediatric Crohn's disease: 5-year analyses of the EUROKIDS Registry. Inflamm Bowel Dis (2013) 19(2):378-85. doi:10.1002/ibd.23008

20. Van Limbergen J, Russell RK, Drummond HE, Aldhous MC, Round NK, Nimmo ER, et al. Definition of phenotypic characteristics of childhood-onset inflammatory bowel disease. Gastroenterology (2008) 135(4):1114-22. doi:10.1053/j.gastro.2008.06.081
21. Onderdonk AB, Hermos JA, Bartlett JG. The role of the intestinal microflora in experimental colitis. Am J Clin Nutr (1977) 30(11):1819-25.

22. Onderdonk AB, Hermos JA, Dzink JL, Bartlett JG. Protective effect of metronidazole in experimental ulcerative colitis. Gastroenterology (1978) 74(3):521-6.

23. Holgersen K, Kvist PH, Markholst H, Hansen AK, Holm TL. Characterisation of enterocolitis in the piroxicam-accelerated interleukin-10 knock out mouse a model mimicking inflammatory bowel disease. JCrohns Colitis (2014) 8(2):147-60. doi:10.1016/j.crohns.2013.08.002

24. Machiels K, Sabino J, Vandermosten L, Joossens M, Arijs I, de Bruyn M, et al. Specific members of the predominant gut microbiota predict pouchitis following colectomy and IPAA in UC. Gut (2017) 66(1):79-88. doi:10.1136/ gutjnl-2015-309398

25. Vineis JH, Ringus DL, Morrison HG, Delmont TO, Dalal S, Raffals LH, et al. Patient-specific bacteroides genome variants in pouchitis. MBio (2016) 7(6):e01713-16. doi:10.1128/mBio.01713-16

26. Onderdonk AB, Steeves RM, Cisneros RL, Bronson RT. Adoptive transfer of immune enhancement of experimental ulcerative colitis. Infect Immun (1984) 46(1):64-7.

27. Onderdonk AB, Cisneros RL, Bronson RT. Enhancement of experimental ulcerative colitis by immunization with Bacteroides vulgatus. Infect Immun (1983) 42(2):783-8.

28. Markowitz J, Kugathasan S, Dubinsky M, Mei L, Crandall W, LeLeiko N, et al. Age of diagnosis influences serologic responses in children with Crohn's disease: a possible clue to etiology? Inflamm Bowel Dis (2009) 15(5):714-9. doi:10.1002/ibd.20831

29. Iliev ID, Funari VA, Taylor KD, Nguyen Q, Reyes CN, Strom SP, et al. Interactions between commensal fungi and the C-type lectin receptor Dectin-1 influence colitis. Science (2012) 336(6086):1314-7. doi:10.1126/ science. 1221789

30. Breeling JL, Onderdonk AB, Cisneros RL, Kasper DL. Bacteroides vulgatus outer membrane antigens associated with carrageenan-induced colitis in guinea pigs. Infect Immun (1988) 56(7):1754-9.

31. Al-Suhail AA, Reid PE, Culling CF, Dunn WL, Clay MG. Studies of the degraded carrageenan-induced colitis of rabbits. I. Changes in the epithelial glycoprotein $\mathrm{O}$-acylated sialic acids associated with ulceration. Histochem J (1984) 16(5):543-53. doi:10.1007/BF01041355

32. Chong AS, Parish CR. Nonimmune lymphocyte-macrophage interaction. I. Quantification by an automated colorimetric assay. Cell Immunol (1985) 92(2):265-76. doi:10.1016/0008-8749(85)90008-5

33. Tsuji RF, Hoshino K, Noro Y, Tsuji NM, Kurokawa T, Masuda T, et al. Suppression of allergic reaction by lambda-carrageenan: toll-like receptor 4/MyD88-dependent and -independent modulation of immunity. Clin Exp Allergy (2003) 33(2):249-58. doi:10.1046/j.1365-2222.2003. 01575.x

34. Wei W, Feng W, Xin G, Tingting N, Zhanghe Z, Haimin C, et al. Enhanced effect of kappa-carrageenan on TNBS-induced inflammation in mice. Int Immunopharmacol (2016) 39:218-28. doi:10.1016/j.intimp.2016.07.031

35. Wu W, Zhen Z, Niu T, Zhu X, Gao Y, Yan J, et al. kappa-Carrageenan enhances lipopolysaccharide-induced interleukin- 8 secretion by stimulating the Bcl10-NF-kappaB pathway in HT-29 cells and aggravates C. freundiiinduced inflammation in mice. Mediators Inflamm (2017) 2017:8634865. doi: $10.1155 / 2017 / 8634865$

36. Weiner ML, Ferguson HE, Thorsrud BA, Nelson KG, Blakemore WR, Zeigler B, et al. An infant formula toxicity and toxicokinetic feeding study on carrageenan in preweaning piglets with special attention to the immune system and gastrointestinal tract. Food Chem Toxicol (2015) 77:120-31. doi:10.1016/ j.fct.2014.12.022

37. Chassaing B, Koren O, Goodrich JK, Poole AC, Srinivasan S, Ley RE, et al. Dietary emulsifiers impact the mouse gut microbiota promoting colitis and metabolic syndrome. Nature (2015) 519(7541):92-6. doi:10.1038/ nature 14232

38. Chassaing B, Van de Wiele T, Gewirtz A. O-013 dietary emulsifiers directly impact the human gut microbiota increasing its pro-inflammatory potential and ability to induce intestinal inflammation. Inflamm Bowel Dis (2017) 23(Suppl 1):S5. doi:10.1097/01.MIB.0000512523.29952.6f

39. Desai MS, Seekatz AM, Koropatkin NM, Kamada N, Hickey CA, Wolter M, et al. A dietary fiber-deprived gut microbiota degrades the colonic mucus barrier and enhances pathogen susceptibility. Cell (2016) 167(5):1339.e-53.e. doi:10.1016/j.cell.2016.10.043 
40. United States Food and Drug Administration. Questions and Answers for Industry on Dietary Fiber. United States Department of Health and Human Services (2017). Available from: https://www.fda.gov/Food/ IngredientsPackagingLabeling/LabelingNutrition/ucm528582.htm

41. Malik F, Okhuysen P, Alousi A, Shpall E, Shelburne S, Petrosino J, et al. Fecal Indole Correlates with Loss of Microbiome Diversity in Hematopoietic Stem Cell Transplant (HSCT) Recipients with and without Intestinal Graft versus Host Disease (iGVHD). San Diego: Paper presented at: IDWeek 2015 (2015).

42. Buffie CG, Bucci V, Stein RR, McKenney PT, Ling L, Gobourne A, et al. Precision microbiome reconstitution restores bile acid mediated resistance to Clostridium difficile. Nature (2015) 517(7533):205-8. doi:10.1038/nature13828

43. Menard S, Cerf-Bensussan N, Heyman M. Multiple facets of intestinal permeability and epithelial handling of dietary antigens. Mucosal Immunol (2010) 3(3):247-59. doi:10.1038/mi.2010.5

44. Odenwald MA, Turner JR. Intestinal permeability defects: is it time to treat? Clin Gastroenterol Hepatol (2013) 11(9):1075-83. doi:10.1016/j.cgh.2013.07.001

45. Choi HJ, Kim HG, Kim J, Park SH, Park J, Oh CG, et al. Pro-apoptotic action of macrophage inhibitory cytokine 1 and counteraction of activating transcription factor 3 in carrageenan-exposed enterocytes. Toxicol Lett (2014) 231(1):1-8. doi:10.1016/j.toxlet.2014.08.022

46. Bikker FJ, Ligtenberg AJ, Nazmi K, Veerman EC, van't Hof W, Bolscher JG, et al. Identification of the bacteria-binding peptide domain on salivary agglutinin (gp-340/DMBT1), a member of the scavenger receptor cysteine-rich superfamily. J Biol Chem (2002) 277(35):32109-15. doi:10.1074/jbc.M203788200

47. Rosenstiel P, Sina C, End C, Renner M, Lyer S, Till A, et al. Regulation of DMBT1 via NOD2 and TLR4 in intestinal epithelial cells modulates bacterial recognition and invasion. J Immunol (2007) 178(12):8203-11. doi:10.4049/ jimmunol.178.12.8203

48. End C, Bikker F, Renner M, Bergmann G, Lyer S, Blaich S, et al. DMBT1 functions as pattern-recognition molecule for poly-sulfated and polyphosphorylated ligands. Eur J Immunol (2009) 39(3):833-42. doi:10.1002/ eji.200838689

49. Bhattacharyya S, Liu H, Zhang Z, Jam M, Dudeja PK, Michel G, et al. Carrageenan-induced innate immune response is modified by enzymes that hydrolyze distinct galactosidic bonds. J Nutr Biochem (2010) 21(10):906-13. doi:10.1016/j.jnutbio.2009.07.002

50. Chen H, Wang F, Mao H, Yan X. Degraded lambda-carrageenan activates NF-kappaB and AP-1 pathways in macrophages and enhances LPSinduced TNF-alpha secretion through AP-1. Biochim Biophys Acta (2014) 1840(7):2162-70. doi:10.1016/j.bbagen.2014.03.011

51. Jiang HY, Wang F, Chen HM, Yan XJ. kappa-carrageenan induces the disruption of intestinal epithelial Caco-2 monolayers by promoting the interaction between intestinal epithelial cells and immune cells. Mol Med Rep (2013) 8(6):1635-42. doi:10.3892/mmr.2013.1726

52. Suez J, Korem T, Zeevi D, Zilberman-Schapira G, Thaiss CA, Maza O, et al. Artificial sweeteners induce glucose intolerance by altering the gut microbiota. Nature (2014) 514(7521):181-6. doi:10.1038/nature13793

53. Bhattacharyya S, Dudeja PK, Tobacman JK. Tumor necrosis factor alphainduced inflammation is increased but apoptosis is inhibited by common food additive carrageenan. J Biol Chem (2010) 285(50):39511-22. doi:10.1074/jbc. M110.159681

54. Joint FAO/WHO Expert Committee on Food Additives. Evaluation of Certain Food Additives and Contaminants. WHO Technical Report Series. Rome, Italy: Fifty-Seventh Report of the Joint FAO/WHO Expert Committee on Food Additives (2001), 909.

55. United States Food and Drug Administration. Select Committee on GRAS Substances (SCOGS) Opinion: Carboxymethyl Cellulose (Packaging) and Sodium Carboxymethyl Cellulose. United States Department of Health and Human Services (2015). Available from: https://www.fda.gov/food/ingredientspackaginglabeling/gras/scogs/ucm261244.htm

56. Salunke S, Giacoia G, Tuleu C. The STEP (safety and toxicity of excipients for paediatrics) database. Part 1-A need assessment study. Int J Pharm (2012) 435(2):101-11. doi:10.1016/j.ijpharm.2012.05.004
57. Salunke S, Brandys B, Giacoia G, Tuleu C. The STEP (safety and toxicity of excipients for paediatrics) database: part 2 - the pilot version. Int J Pharm (2013) 457(1):310-22. doi:10.1016/j.ijpharm.2013.09.013

58. Dietary and other risk factors of ulcerative colitis. A case-control study in Japan. Epidemiology Group of the Research Committee of Inflammatory Bowel Disease in Japan. J Clin Gastroenterol (1994) 19(2):166-71.

59. D'Souza S, Levy E, Mack D, Israel D, Lambrette P, Ghadirian P, et al. Dietary patterns and risk for Crohn's disease in children. Inflamm Bowel Dis (2008) 14(3):367-73. doi:10.1002/ibd.20333

60. Ruemmele FM, Veres G, Kolho KL, Griffiths A, Levine A, Escher JC, et al. Consensus guidelines of ECCO/ESPGHAN on the medical management of pediatric Crohn's disease. JCrohns Colitis (2014) 8(10):1179-207. doi:10.1016/j.crohns.2014.04.005

61. Van Limbergen J, Haskett J, Griffiths AM, Critch J, Huynh H, Ahmed N, et al. Toward enteral nutrition for the treatment of pediatric Crohn disease in Canada: a workshop to identify barriers and enablers. Can J Gastroenterol Hepatol (2015) 29(7):351-6. doi:10.1155/2015/509497

62. Quince C, Ijaz UZ, Loman N, Eren AM, Saulnier D, Russell J, et al. Extensive modulation of the fecal metagenome in children with Crohn's disease during exclusive enteral nutrition. Am J Gastroenterol (2015) 110(12):1718-1729; quiz 1730. doi:10.1038/ajg.2015.357

63. Gerasimidis K, Bertz M, Hanske L, Junick J, Biskou O, Aguilera M, et al. Decline in presumptively protective gut bacterial species and metabolites are paradoxically associated with disease improvement in pediatric Crohn's disease during enteral nutrition. Inflamm Bowel Dis (2014) 20(5):861-71. doi:10.1097/MIB.0000000000000023

64. Dunn KA, Moore-Connors J, MacIntyre B, Stadnyk AW, Thomas NA, Noble A, et al. Early changes in microbial community structure are associated with sustained remission after nutritional treatment of pediatric Crohn's disease. Inflamm Bowel Dis (2016) 22(12):2853-62. doi:10.1097/ MIB. 0000000000000956

65. Dunn KA, Moore-Connors J, MacIntyre B, Stadnyk A, Thomas NA, Noble A, et al. The gut microbiome of pediatric Crohn's disease patients differs from healthy controls in genes that can influence the balance between a healthy and dysregulated immune response. Inflamm Bowel Dis (2016) 22(11):2607-18. doi:10.1097/MIB.0000000000000949

66. Lewis JD, Chen EZ, Baldassano RN, Otley AR, Griffiths AM, Lee D, et al. Inflammation, antibiotics, and diet as environmental stressors of the gut microbiome in pediatric Crohn's disease. Cell Host Microbe (2015) 18(4): 489-500. doi:10.1016/j.chom.2015.09.008

67. Lee D, Baldassano RN, Otley AR, Albenberg L, Griffiths AM, Compher C, et al. Comparative effectiveness of nutritional and biological therapy in North American children with active Crohn's disease. Inflamm Bowel Dis (2015) 21(8):1786-93. doi:10.1097/MIB.0000000000000426

68. Levine A, Wine E. Effects of enteral nutrition on Crohn's disease: clues to the impact of diet on disease pathogenesis. Inflamm Bowel Dis (2013) 19(6):1322-9. doi:10.1097/MIB.0b013e3182802acc

69. Suskind DL, Cohen SA, Brittnacher MJ, Wahbeh G, Lee D, Shaffer ML, et al. Clinical and fecal microbial changes with diet therapy in active inflammatory bowel disease. JClin Gastroenterol (2016). doi:10.1097/ MCG.0000000000000772

Conflict of Interest Statement: JVL has participated in an advisory board for Nestlé and has received speaking fees and research support from Nestlé. The other authors declare no conflict of interest.

Copyright $\odot 2017$ Martino, Van Limbergen and Cahill. This is an open-access article distributed under the terms of the Creative Commons Attribution License (CC BY). The use, distribution or reproduction in other forums is permitted, provided the original author(s) or licensor are credited and that the original publication in this journal is cited, in accordance with accepted academic practice. No use, distribution or reproduction is permitted which does not comply with these terms. 